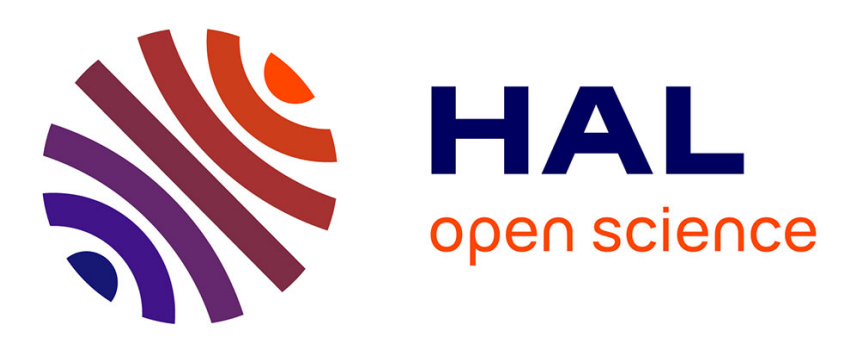

\title{
An innovative experimental approach aiming to understand and quantify the actual fire hazards of ionic liquids
}

Alpha-Oumar Diallo, Alexander B. Morgan, Christophe Len, Guy Marlair

\section{To cite this version:}

Alpha-Oumar Diallo, Alexander B. Morgan, Christophe Len, Guy Marlair. An innovative experimental approach aiming to understand and quantify the actual fire hazards of ionic liquids. Energy \& Environmental Science, 2013, 6 (3), pp.699-710. 10.1039/c2ee23926d . ineris-00961793

HAL Id: ineris-00961793

https://hal-ineris.archives-ouvertes.fr/ineris-00961793

Submitted on 20 Mar 2014

HAL is a multi-disciplinary open access archive for the deposit and dissemination of scientific research documents, whether they are published or not. The documents may come from teaching and research institutions in France or abroad, or from public or private research centers.
L'archive ouverte pluridisciplinaire HAL, est destinée au dépôt et à la diffusion de documents scientifiques de niveau recherche, publiés ou non, émanant des établissements d'enseignement et de recherche français ou étrangers, des laboratoires publics ou privés. 


\title{
An innovative experimental approach aiming to understand and quantify the actual fire
} hazards of ionic liquids

Alpha-Oumar Diallo, ${ }^{a, b}$ Alexander B. Morgan, ${ }^{c}$ Christophe Len ${ }^{b}$ and Guy Marlair ${ }^{* a}$

${ }^{a}$ Institut National de l'Environnement Industriel et des Risques (INERIS), Parc Technologique Alata, BP2, 60550 Verneuil-en-Halatte, France

${ }^{b}$ UTC-ESCOM, EA 4297, Transformations Intégrées de la Matière Renouvelable, Centre de Recherches de Royallieu, BP 20529, F-60205 Compiègne Cedex, France

${ }^{c}$ University of Dayton Research Institute (UDRI), Multiscale Composites and Polymers Division, 300 College Park, Dayton, OH 45469-0160, USA

\begin{abstract}
The aim of the study is to produce advanced knowledge on the thermal and combustion hazard profiles of ionic liquids based on an original multiscale combined experimental approach. Experimental tools have been implemented and used to a) obtain actual measurements of theoretical heats of combustion of imidazolium-based and phosphoniumbased ionic liquids by use of a bomb calorimetry; b) provide access to fundamental flammability properties of these chemicals through the use of Pyrolysis Combustion Flow Calorimetry c) determine actual behaviour of ionic liquids in fire conditions, from learnings obtained by a series of combustion tests performed on 12 ionic liquids by use of the INERIS Fire Propagation Apparatus. Results so far confirm that the combustibility potential as well as the fire behaviour must be assessed on a case by case approach and is often dictated by ionic liquid chemical structure. The study also illustrates how the data obtained by our innovative procedure allows for consistent fire safety engineering studies serving the green use of ionic liquids in a contextual way. The work has opened a new perspective of collaborative work towards the development of a dedicated and pertinent methodology aiming at characterizing the comprehensive physicochemical hazards profile of ionic liquids.
\end{abstract}

*Corresponding author: guy.marlair@ineris.fr 


\section{Introduction}

Ionic liquids (ILs) are advanced chemicals promised by many people to have a brilliant future in a number of strategic applications that might provide a greener future in chemistry and energy related technological developments. ${ }^{1-10}$ In particular, key emerging uses in the sector of energy and environmental technologies are regularly reported in the literature. ${ }^{11-13}$ One of main advantage systematically claimed for ILs is their improved operational safety in comparison to conventional solvents. This is based on their negligible vapour pressure and most often misleadingly reported "non flammability", not only in manufacturer commercial literature, but also in scientific journals. Indeed, the flammability (or non flammability property) of a given material must always be related to specific conditions prevailing during testing (see ISO 13943 fire safety vocabulary). When considering liquids, flammability is assessed according to flash point values, various threshold values being considered in different regulatory frameworks to rate a liquid as "flammable" or "non flammable" in the context of those regulations. For instance, in the Classification Labelling and Packaging regulation, ${ }^{14}$ flammable liquids are those having a flash point below or equal $60^{\circ} \mathrm{C}$ whereas in the Globally Harmonized System, ${ }^{15}$ values as high as $93^{\circ} \mathrm{C}\left(\right.$ e.g. in $4^{\text {th }}$ category) and even higher according to regulatory frameworks considered, would still qualify same liquids as flammable liquids. Subsequently, the only true definition of a flammable liquid is a liquid which is capable of burning with flames. This is why, reporting on ILs as non flammable liquids per se may be misleading, even if somewhat true in the appropriate regulatory context. We must also keep in mind that ILs cover a very wide range of chemicals, numbering in millions if not more ${ }^{16}$ and that some ILs may be tuned as to be combustible by design. ${ }^{17}$ Additionally, authors of this manuscript have reported elsewhere why, in the case of ILs, the measurement of flash point do not reflect their actual flammability potential. ${ }^{18}$ Indeed, other limits of the flash point criterion is bound to the fact that in apparatus developed to measure flashpoint, the flammability is implicitly related to the flaming combustion of a mixture or the vapour phase of the studied liquid and air, which is not necessarily the phenomenon observed with ILs. At last, whatever is the retained method to rate a material as a "non flammable" material, this does not mean that it should be considered as "non combustible" and consequently does not imply that the material in question is $100 \%$ safe to use near heat or fire sources. As it was reported by Smiglak, ${ }^{17}$ decomposition products from the thermal decomposition of ILs may be highly and purposely combustible, and indeed, others have seen this as well. ${ }^{19-22}$ Furthermore, due to the variety of chemical structures available with ILs, 
noxious emissions resulting from free burning of these materials could reveal far more different and possibly more exotic as those generated from combustion of existing organic solvents that ILs seek to replace. Clearly there is much more to be studied on these materials and most likely, different tests will be needed to assess the fire hazard of ILs in laboratory and industrial settings. Just as new technologies entering the workplace and home have resulted in new fire standards, very likely ILs will require different fire tests to certify them as safe or of acceptable risk in laboratory and industrial fire risk scenarios.

The present work is a continuation of our previous research to (i) quantify the heat release of ILs; (ii) provide theoretical and experimental data that can quantify the flammability of ILs in all its aspects (ease of ignition, mass burning rate, heat release rate, fire-induced toxicity data...); (iii) provide first guidance to fire safety engineers about how to handle this material in their assessments. Through the use of heat of combustion measurements, pyrolysis combustion flow calorimetry, and the fire propagation apparatus, we show that not all ILs have the same levels of heat release/flammability even though they may have similar predecomposition thermal properties.

\section{Materials and methods}

\subsection{Ionic liquids}

Samples of Imidazolium-Based Ionic Liquids (IMBILs) associated with different counteranions were kindly supplied by BASF, respectively under the generic brand commercial names Basionics. Samples of a second family of Phosphonium-based Ionic Liquids (PBILs) associated with different counter-anions were also made available to the laboratory for testing, due to courtesy of the CYTEC Company. Designations of materials and information on their technical grades are given in table 1. Schematic representations of all the studied ILs are in addition shown in figure 1. Experimental tests were performed on the products as received, without any further purification step.

\subsection{Oxygen Bomb calorimetry}

The theoretical energy of combustion of ILs was measured in an oxygen bomb calorimeter (Model 1108P, Oxygen Combustion Bomb, Parr Instrument Co., Moline, Illinois) following ASTM D240 protocol. $^{23}$ Prior to sample testing, the bomb calorimeter was calibrated by combusting ten tests of approximately $1 \mathrm{~g}$ of standard benzoic acid (NBS Thermochemical Standard, 39g) which has a known heat of combustion of $26.454 \mathrm{MJ} / \mathrm{kg}$. Preliminary testing has revealed that the ignition did not result in effective combustion in the case of all ILs 
samples by use of the standard ignition procedure in the bomb calorimetry. Thus, in order to achieve actual and effective ignition of ILs during the process of combustion in oxygen, pharmaceutical paraffin oil, which heat of combustion was firstly measured, was mixed in predetermined quantity with the samples. A weighed sample of approximately 0.21 to $0.35 \mathrm{~g}$ of IL is placed in a platinum crucible and assembled in the bomb calorimeter. The vessel is then pressurized with pure oxygen to 3.0 $\mathrm{MPa}$ for the test and placed inside a bath containing 2 litres of water in an insulated jacket. A motorized stirrer is placed inside the water bath to circulate the water around the bomb creating a uniform temperature. The equilibrium rise of water temperature due to combustion in the bomb calorimeter is recorded using a precision thermistor (Omega Model 1417E). The amount energy released by paraffin oil was subtracted from the total energy released in the bomb to compensate for the added charge.

Ignition correction $\mathrm{e}_{1}$ is made for the heat contribution from burning of nitrogen trapped in the bomb to form nitric acid. It was assumed that 10 calories is a good correction for $\mathrm{e}_{1}$. A correction value $e_{2}$ for the combustion of sulphur leading to sulphur trioxide forming sulphuric acid instead of sulphur dioxide is also applied. This adjustment is equal to 13.7 calories per percentage of sulphur in the sample mass. Finally, for the fuse wire an adjustment e 3 equal to 15 calories is applied. The gross heat of combustion or high heating value (HHV) is then calculated as:

$$
H H V_{I L}=\frac{W \cdot \Delta T-e_{1}-e_{2}-e_{3}-H H V_{\text {paraffin }} \cdot m_{\text {paraffin }}}{m_{I L}}
$$

where $\mathrm{W}$ is the energy equivalent of the calorimeter obtained from the calibration; $\Delta \mathrm{T}$ is the temperature rise; $\mathrm{HHV}_{\text {paraffin }}, \mathrm{m}_{\text {paraffin }}$ and $\mathrm{m}_{\mathrm{IL}}$ are the gross heat of combustion, weight of paraffin and IL, respectively. Three replicates are performed for each sample, and the typical relative error was less than $0.20 \%$.

\subsection{Microscale Combustion Calorimetry}

The microscale combustion calorimeter also known as Pyrolysis Combustion Flow Calorimeter $(\mathrm{PCFC})^{24}$ is a new small-scale instrument and standardized method (ASTM D7309-07) $)^{25}$ for measuring at small scale the heat release from combustible materials via oxygen consumption calorimetry. Samples in the range of 5-50 mg in size are sufficient, making it a potent technique for quantification of material flammability without consuming large amounts of material. Indeed, with the PCFC, one can obtain fundamental heat release data for a material (originally for plastics) as a function of its chemical structure, and can 
study the heat release rate $v s$. temperature, as well as the actual heat of combustion behaviour for a wide range of material flammability studies, as related in many works. ${ }^{26-30}$

The samples provided by CYTEC were tested with the microscale combustion calorimeter using a heating rate of $1^{\circ} \mathrm{C}$ per second, from 100 to $700^{\circ} \mathrm{C}$ using Method A of ASTM D730907. The working principle of the instrument is illustrated in figure 2. The sample is pyrolyzed under nitrogen atmosphere initially, and the gases from pyrolysis zone are pushed into a $900^{\circ} \mathrm{C}$ furnace, where they are combusted in the presence of oxygen. Each sample was run in triplicate as per the standard to evaluate reproducibility of the flammability measurements.

\subsection{Fire Propagation Apparatus (Tewarson Calorimetry)}

The fire behaviour of ILs was performed using the Tewarson calorimeter also covered under the name of Fire Propagation Apparatus (FPA) by different standards, namely NFPA 287, ${ }^{31}$ ASTM E2058, ${ }^{32}$ and ISO $12136 .{ }^{33}$ This bench-scale fire calorimeter implemented at INERIS some 15 years ago has been described in detail by Brohez et al. ${ }^{34,35}$ and was recently used by Ribière et al. ${ }^{36}$ on the fire-induced hazards of Li-ion battery cells. It belongs to the family of fire calorimeters that are bench scale multipurpose testing apparatuses focusing on the characterization of burning behaviour of materials and products in fire conditions. Figure 3 represent a schematic drawing of the equipment as well as a photographic illustration of the apparatus installed in INERIS fire lab. Testing capability of the equipment encompasses ignitability, fire propagation potential, thermal and chemical characteristics in fire condition. Repeatability and reproducibility of data count among the major advantages of the equipment ${ }^{37}$ together with its capacity of revealing atypical fire phenomena, like-liquid phase decomposition process of organophosphorous pesticides. ${ }^{38}$ In particular, parametric tests on product samples of about $50 \mathrm{~g}$ under controlled air intake allow for characterizing fire behaviour of the studied material or product (liquid, solids, gases) on the full spectrum of fire conditions (fuel rich or fuel lean). Scientific-sound diagnosis of the fire behaviour of materials is achieved thanks to the access to key measures such as mass loss, HRR by application of fire calorimetry laws based on the assessment of oxygen consumption (OC) ${ }^{39}$ and carbon dioxide generation $(\mathrm{CDG}),{ }^{40}$ measurements of fire effluent concentrations and related emission yields allowing for an evaluation of pollutants and fire toxicity issues.

In this study, preliminary tests were performed in order to choose the most suitable operating conditions, according to ignitability and fire propagation conditions. IL samples (50-65 g) were poured in a glass sample holder. An external heat flux of $50 \mathrm{~kW} / \mathrm{m}^{2}$ was set in operation by four infrared heaters in an air-flushed jacket, allowing the sample to be heated to a 
temperature where its vapours or flammable decomposition products can be ignited by an electric spark or pilot flame. These preliminary tests revealed good resistance to ignition for all samples and apart from [EMIM][DCA] sample, no sustained combustion without application of an external heat flux. According to these observations, testing protocols for reference burning tests were adapted as follow: an external flux of $50 \mathrm{~kW} / \mathrm{m}^{2}$ was applied until ignition was observed, and after ignition external heat flux was diminished to $25 \mathrm{~kW} / \mathrm{m}^{2}$. In the case of [EMIM][DCA] the test was performed with reduced initial mass of sample and by stopping the external flux after ignition, according to observed reactivity in the preliminary experiment with this chemical.

Smoke analysis was performed by use of an online Fourier Transform Infrared (FTIR) spectrometer calibrated over 20 gases for derivation of $\mathrm{CO}_{2}, \mathrm{CO}, \mathrm{SO}_{2}, \mathrm{NOx}, \mathrm{HCN}, \mathrm{HCl}, \mathrm{BF}_{3}$ and HF concentrations and mass release rate versus time. The continuous measurement of exhaust gas opacity is done by an opacimeter based on the Beer-Lambert's law, assuming that soot is the only condensed matter responsible for smoke incapacity. Inlet air flow was adjusted to obtain well ventilated fire conditions, as reflected by an equivalence ratio phi parameter [(fuel/air) vs. (fuel/air) $\left.)_{\text {stoechiometric }}\right] \ll 1$.

\subsection{First order assessment of fire-induced toxicity}

The toxicity assessment of combustion products involving ILs in accidental pool fires is provided here by means of a simplified model of dispersion of pollutants in a confined environment and illustrated in a theoretical case study. We consider a pool fire of an IL with a given surface $S\left(\mathrm{~m}^{2}\right)$ developing in an enclosure of volume $\mathrm{V}\left(\mathrm{m}^{3}\right)$. The room is subject to a constant air renewal rate corresponding to an inlet flow rate $\mathrm{Q}\left(\mathrm{Nm}^{3} / \mathrm{h}\right)$, as illustrated in figure 4. In this configuration, we assume that the pollutants are evenly distributed in the entire room (which means the assumption that the room behaves as a well mixed reactor) . With such simplified assumption, the evolution of concentration $\mathrm{Cp}\left(\mathrm{mg} / \mathrm{Nm}^{3}\right)$ of a pollutant $\mathrm{p}$ is then given by equation (2):

$$
V \frac{d C_{p} t}{d t}=\left[P_{p}+Q \cdot C_{i n}-Q \cdot C_{p} t\right]
$$

where $P_{p}$ and $C_{i n}$ are the rate of produced pollutant $p$ (expressed in $m g / h$ ) and the inlet concentration of pollutant $\mathrm{p}$ (expressed in $\mathrm{mg} / \mathrm{Nm}^{3}$ ), respectively. Thus, if we may assume $\mathrm{P}_{\mathrm{p}}$ as a constant against the time interval of interest, equation (2) can be solved as a system of 
differential equations of first order in $\mathrm{C}(\mathrm{t})$, and hence, concentration versus time between final and initial conditions may be expressed by equation (3):

$$
C_{p, f} \quad t=C_{p, 0} e^{-\frac{Q \cdot t}{V}}+\left(\frac{P_{p}}{Q}-C_{p, i n}\right)\left(1-e^{-\frac{Q \cdot t}{V}}\right)
$$

However, combustion conditions change continuously with time. Thus, we have considered time intervals, in consistency to periodicity of data acquisition scans to discretize equation (3) and use results obtained for concentration of pollutant $\mathrm{p}$ as initial conditions for the implementation of the calculation of the concentration of same pollutant on the next interval. Assuming that fresh air is blown into the room free of considered pollutants and, at time zero the concentration of pollutant $\mathrm{p}$ in the room is zero, the calculations lead to the following equation, for each pollutant:

$$
C_{p, i}=C_{p, i-1} e^{-\tau \cdot \Delta t_{i}}+\frac{P_{p, i}}{Q} 1-e^{-\tau \cdot \Delta t_{i}}
$$

where $\tau\left(\mathrm{h}^{-1}\right)=\mathrm{Q} / \mathrm{V}$ is the number of fresh air renewals by hour and $\Delta \mathrm{t}(\mathrm{h})$ is the time step. The final step in the methodology consists in converting concentrations of toxics resulting from previous calculations in state of the art fire-induced toxicity indices relating to given critical conditions, as developed by ISO TC92.

In practice, Fractional Effective Dose (FED), respectively Fractional Effective Concentration (FEC), are computed for considering asphyxiant effects, respectively irritant effects of fire gases, assuming a dose effect for asphyxiants and a concentration effect for irritant gases, as referred to in the latest version of ISO $13571 .{ }^{41}$ Corresponding parameters, $\mathrm{X}_{\mathrm{FED}}$ and $\mathrm{X}_{\mathrm{FEC}}$ can be obtained from the evolution of pollutant concentrations in the room using equation (5) and equation (6), respectively:

$$
\begin{array}{r}
X_{F E D}=\sum_{t_{1}}^{t_{2}} \frac{C O}{35000} \Delta t+\sum_{t_{1}}^{t_{2}} \frac{H C N^{2.36}}{1.2 \times 10^{6}} \Delta t \quad \text { (5) } \\
X_{F E C}=\frac{H C l}{F_{H C l}}+\frac{H B r}{F_{H B r}}+\frac{H F}{F_{H F}}+\frac{S O_{2}}{F_{S_{2}}}+\frac{N_{2}}{F_{N_{2}}} \\
+\frac{\text { acrolein }}{F_{\text {acrolein }}}+\frac{\text { formaldehyde }}{F_{\text {formaldehyde }}}+\sum \frac{\text { irri } \tan t}{F_{C_{i}}}
\end{array}
$$

Critical values used here in equation (5) and equation (6) refer to escape impairment that is supposed reached for $\mathrm{X}_{\mathrm{FED}}$ or $\mathrm{X}_{\mathrm{FEC}}$ equal to 1 for ordinary sensitive people. 


\section{Results and discussion}

\subsection{Complete heats of combustion}

The results obtained for all tested ILs by use of the oxygen bomb calorimeter are given in table 2. These values are averages of triplicate determinations. For comparison, predicted values of same ILs making use of the purpose-built model ${ }^{22}$ are given in first column in the same table. As can be seen from the table 2, predicted values of heats of combustion of ILs from the IL-dedicated model were strongly correlated with those obtained from the bomb calorimeter, with an $\mathrm{R}^{2}$ of 0.99 as illustrated in figure 5 . This is noteworthy in that, the model based on a quantitative structure-property relationship was initially developed from a database that did not contain any PBILs and still gives very good correlation to real world experimental results. This confirms that this model, based on weight percentages of main elements in ILs, demonstrated robust prediction capabilities for heats of combustion of ILs. Another conclusion of this experimental part of the work is that combustibility of ILs cannot be ignored, as analysed in terms of potential fire loads that rise up to $40 \mathrm{MJ} / \mathrm{kg}$ in the case of the PBILs.

\subsection{Pyrolysis Combustion Flow Calorimetry data}

Typical results from the PCFC focus on heat release measurements and the results that were recorded from each of the materials are shown in table 3 . The data in the table covers the following measurements:

- Char yield: this is obtained by measuring the sample mass before and after pyrolysis. The higher the char yield, the more carbon/inorganic material left behind. As more carbon is left behind, the total heat release should decrease.

- HRR Peak(s): this was the recorded peak maximum of HRR found during each experiment. The higher the HRR value, the more heat given off at that event. This value roughly correlates to peak heat release rate that would be obtained by the cone calorimeter (ISO 5660), or by the Tewarson Apparatus. Where more than one number is shown in table 3 , this indicates that the heat release is a multi-peak heat release, which would be due to multi-step thermal decomposition of the PBILs.

- $\quad$ HRR peak(s) Temperature: this correspond to temperatures at which the HRR peaks are observed. 
- Total HR: this is the total heat release for the sample, which is the area under the curve(s) for each sample analysis.

- Char notes: description of the sample residues collected from each test.

From the data in table 3, it is clear that the chemical structure of the ILs has an effect on the measured flammability and thermal decomposition / heat release rates of each material. The anion of each IL appears to have a strong influence on char yields and total HR. For instance, this can be examined if we compare $\left[\mathrm{P}_{6,6,6,14}\right][\mathrm{Cl}],\left[\mathrm{P}_{6,6,6,14}\right]\left[\left(\mathrm{iC}_{8}\right)_{2} \mathrm{PO}_{2}\right],\left[\mathrm{P}_{6,6,6,14}\right][\mathrm{DCA}]$, and $\left[\mathrm{P}_{6,6,6,14}\right][\mathrm{TFSI}]$ which all have the same cation $\left[\mathrm{P}_{6,6,6,14}\right]$ but differing anions. From this comparison, the dicyanamide (DCA) and the bis(trifluoromethylsulfonyl)imide (TFSI) clearly reduce flammability by increasing char yields in fire conditions mimicked in the PCFC, but vapour phase heat release reductions provided by decomposition chemistry of these two anions cannot be ruled out either. For example, the TFSI does show greatly lowered initial peak HRR values when compared to the DCA which may come from the evolution of fluoride and sulphur oxides in the TFSI. Ultimately, each of these ILs has its own flammability as dictated by its chemical structure and so some of these results will be useful to mapping out chemical structure / heat release properties appropriate for ILs, as has been done already for polymers via PCFC. ${ }^{42}$

It should be noted here that the PCFC results measure the heat release of the material when the PBILs is pyrolyzed/thermally decomposed under an inert atmosphere followed by a subsequent combustion in a furnace where oxygen in present. The significance of this is that in a real fire event, a material only encounters oxygen prior to ignition. Once a material is ignited, all oxygen is consumed at the flame front. This means that post ignition, all flammable material is pyrolyzed and decomposed in an anaerobic manner. Since the PCFC mimics this real fire behaviour (anaerobic thermal decomposition followed by flame front oxidation), the PCFC can provide a realistic measurement of how much heat release could be given off as the material burns. Indeed, some of the results seen here match some of the observations seen in the FPA (section 3.3) in that PBILs did char, even under forced combustion conditions. PCFC alone is not enough to understand IL flammability, but it is a useful tool and since it only consumes 5-10 mg of material per test, it can be a further useful tool for assessing heat release potential at low cost and low consumption of sample, at a an early stage of ILs development. 


\subsection{Fire propagation apparatus tests}

An overview of the results obtained from the combustion of ILs in the Tewarson calorimeter is summarized in table 4 where the following data are listed:

- External heat flux applied $\left(\mathrm{kW} / \mathrm{m}^{2}\right)$

- Initial sample mass (g)

- Overall Mass loss (\%) (Char residue by difference to 100\%)

- Time to ignition (s)

- Average mass loss rate $\left(\mathrm{g} / \mathrm{m}^{2} / \mathrm{s}\right)$

- Peak Mass lost rate $\left(\mathrm{g} / \mathrm{m}^{2} / \mathrm{s}\right)$

- Phi factor

- Actual (effective) heat release (MJ/kg)

- Energy conversion efficiency (\%)

- Pollutants yields (mg of gas/g of sample)

- Carbon, chlorine, fluorine, sulphur and nitrogen conversions efficiency into related combustion products $(\%)$.

The data and the observation made during the tests confirm generally good resistance to ignition of ILs, according to ignition time requested under applied external heat flux in initial phase of the tests $\left(50 \mathrm{~kW} / \mathrm{m}^{2}\right)$. However, once ignition was obtained sustained and flaming combustion phases were observed and characterized, and confirming real combustibility of all the ILs tested as anticipated from oxygen bomb and PCF calorimetry. Once ignited and provided with sufficient heat, ILs will burn and cannot be considered any longer as "nonflammable". The ignition delay of $\left[\mathrm{P}_{6,6,6,14}\right]\left[\left(\mathrm{iC}_{8}\right)_{2} \mathrm{PO}_{2}\right]$, [EMIM][DCA] and $\left[\mathrm{P}_{4,4,4,2}\right][\mathrm{DEP}]$ was not negligible as compared to flammable solvents like hexane or ethanol but rather short (135s, 138s and 140s respectively) as compared to the other ILs (430s for the [EMIM][BF 4$]$ ). Moreover, it was observed that self extinction may occur when external heat flux is set to zero after initial ignition, except for [EMIM][DCA]. It is noteworthy that ILs generally present good to remarkable flame retardancy properties, as mentioned by Armand. ${ }^{43}$ Decomposition temperatures of many ILs generally lies in between $150^{\circ} \mathrm{C}$ up to $400^{\circ} \mathrm{C}$, as studied in differential scanning calorimetry of thermo parametric analysis. ${ }^{44}$ This explained that even 
under significant heat stress $\left(50 \mathrm{~kW} / \mathrm{m}^{2}\right)$, production of flammable mixture flow in our experiments required significant time for ignition to take place. Here again, as the FPA results indicate, confirmed flame retardancy properties of tested ILs do not suppress any fire risk. Provided favourable environmental conditions are achieved, sustained combustion may indeed take place, leading to thermal and chemical threats that vary in nature and intensity for each IL. The combustion rate influencing both thermal and chemical related threats in well ventilated conditions is highly variable. As shown in figure 6a, combustion of [EMIM][DCA] is developing with very fast kinetics with a peak of heat release about $8400 \mathrm{~kW} / \mathrm{m}^{2}$, by far exceeding current values for hydrocarbon pool fires. ${ }^{45}$ This is due to the association of the imidazolium type cation with the dicyanamide anion as reported by Fox. ${ }^{19}$ Figure $6 \mathrm{~b}$ confirms that the heat flow profile reveals unique to each IL, generally significantly lower however as compared to conventional solvents and hydrocarbon fires. For example the combustion of [EMIM][OTf] leads to combustible decomposition products as shown by the appearance of a peak in the reaction medium. The combustion of $[\mathrm{EMIM}]\left[\mathrm{BF}_{4}\right]$ is more typical of that of an hydrocarbon showing a plateau throughout the reaction of oxidation. These results confirm the important role of the anion on the flammability, with the general trend of OTf $>\mathrm{BF}_{4}>\mathrm{MeSO}_{3}>\mathrm{EtOSO}_{3}>\mathrm{DCA}$ when looking which anion opposes to heat release the most.

Similarly to the case of IMBILs, heat release profile for tested PBILs differ from conventional liquid pool fire behaviour, where the combustion of the vapour phase of the burning chemical appears as being the driving phenomenon. Figure 7 a showed that decomposition of condensed PBILs took place, driving in most cases the combustion process in our test conditions. Here also effective heats of combustion showed quite variable. Figure $7 b$ shows the effect of anion on the combustion. The behaviour of PBILs having the same cation $\left[\mathrm{P}_{6,6,6,14}\right]$ follow a general trend ranking as $[\mathrm{TFSI}]>[\mathrm{Cl}]>\left[\left(\mathrm{iC}_{8}\right)_{2} \mathrm{PO}_{2}\right]>[\mathrm{DCA}]$ when looking which anion reduced effective heat of combustion the most. When comparing effective heat release to the theoretical ones, the combustion efficiency varies from 55 to $101 \%$.

Comparison between total heat release from PCFC and FPA calorimeter are illustrated in figure 8 . As can be seen, in a majority of cases, the thermal efficiency of the combustion process remains higher in the PCFC, which seems consistent with more favourable combustion conditions in terms of combustible oxidizer mixture.

Products emission factors characterized in well ventilated conditions reveal that high conversion rates of hetero-atoms in parent toxic effluents are obtained in several cases. The 
combustion of ILs having fluorine elements leads to the formation of HF which condensed vapours attack the quartz glass with production of $\mathrm{SiF}_{4}$. Whereas the presence of fluorine in organo-halogenated materials generally contributes to good flame retardancy of such materials, its conversion into HF in fire environments triggers unique hazards to exposed people and fire fighters and even equipments that may justify due considerations in practical use of ILs in laboratory and industrial settings.

\subsection{Fire induced Toxicity examination of burning ILs}

Data obtained by performing combustion tests in the Tewarson calorimetry (i.e. time to ignition, burning rate, actual heat release rate and emission factors of pollutants) can be used as "source term" information allowing to a researcher to perform contextual assessment of risks pertaining to ILs in the real world. Although tremendous progress has been achieved in that domain of fire safety science, such an evaluation remains a complex issue that requires careful consideration of risk assessment objectives, access to reliable input data, and appropriate selection of modelling tools. Therefore an in-depth examination of this issue is considered out of the scope of this paper. Nevertheless, by considering a fictive case study here as a pedagogic material, we develop hereafter how the combustion data obtained by use of the FPA can be used to address fire induced toxicity issues, in terms of fire safety engineering practice. We consider a case study where a given IL is used in a batch reactor. The following assumption is a worst case fire scenario of likely occurance is the burning in pool-like configuration that involves 10 liters of IL which ignites due to some reason in a building developing an overall volume of $80 \mathrm{~m}^{3}$, behaving as a well stirred reactor and the burning pool is assumed being limited to a surface of $0.06 \mathrm{~m}^{2}$. Due to limited self-sustained potential of combustion of ILs, and expected fast intervention by fire fighters, we assume in addition that only $30 \%$ of the 10 liters of IL will burn ultimately. For the [EMIM][DCA], we assume a complete consumption of the entire liquid in the fire, due to observed fast combustion process. Thus, in these conditions, the escape impairment criteria obtained by concept of FED and FEC for number of fresh air renewals per hour $\tau=3 \mathrm{~h}^{-1}, 5 \mathrm{~h}^{-1}$ and $10 \mathrm{~h}^{-1}$ have been computed and plotted in figure 9 and figure 10, respectively, for IMBILs and PBILs.

Although these trends are illustrated for a fictive case study, with basic assumptions that have limited validity, the curves showing the evolution of FED and FEC indices reveal how the users of our experimental methodology may use the data in order to render the use of the given ILs safer. First observation of figure 9 and figure 10 at first illustrates that the fire- 
induced toxicity potential may clearly differ from one IL to another, due to differences in combustion rates and in nature and rates of fire product releases. In this fictive scenario, the fire one involving the studied ILs examined as the described worst case leads to production of irritant gases in such quantities that fractional effective concentration rises over the critical threshold value for after a few minutes, whichever the air renewal rate is, for both for the IMBILs and the PBILs under consideration. This is due to the release of a large amount of various irritant gases such as $\mathrm{NO}_{\mathrm{x}}, \mathrm{SO}_{2}, \mathrm{HF}, \mathrm{BF}_{3}, \mathrm{CH}_{2} \mathrm{O}$ and $\mathrm{HCl}$, essentially formed from the IL relating anion structure. Only combustion of $\left[\mathrm{P}_{4,4,4,2}\right][\mathrm{DEP}]$ does not produce any irritant pollutant, as shown in table 4 . Thus, in an accidental fire scenario the major toxicity issue involving this chemical would be the asphyxiants released like the CO.

Detailed comparison however shows that the emergency situation would occur sooner or later according to type of IL considered, possibly allowing different fire safety management strategies (smoke gas protection, emergency escape training, pre-planned intervention procedures...) or in some cases requesting a review of the process in order to diminish the seriousness of the ultimate worst case scenario. Dealing with the asphyxiants gases (limited here to $\mathrm{HCN}$ and $\mathrm{CO}$ ), concerned toxic compounds evolution versus time and relating fractional effective dose is significantly affected by the air renewal rate up to the point to offer a possibility to handle the situation in some cases by increasing the ventilation rate of the building in case of a fire, or by setting a high but still reasonable air renewal rate (up to $10 \mathrm{~V} / \mathrm{h}$ ). Indeed, in the considered case study, large air renewal rate may impede the toxic threat resulting from the emission of asphyxiants from burning IMBILs to become ever critical ( $\mathrm{X}_{\mathrm{FED}}$ always below 1) whereas for the PBILs, large renewal rates offer significantly higher evacuation time before escape impairment.

As a reminder, the present exercise has been provided just for illustrating how our experimental approach may help the user to consider safe use of ILs including the way fireinduced toxicity may be taken into consideration. It only gives trends on this latter aspect, as the integral modelling approach based on the use of equations (2) to (6) is very simplistic and considers assumptions that very rapidly find their validity limits. Actual evaluation of fire toxicity issue into the building would require tools to proceed to compartment fire modelling (integrating cold and hot smoke layers and fire plume), relying on the use of a fire risk dedicated zone models like Computational Fluid Modelling. Indeed, for such an exercise, same date qualifying the "source term" of fire gases emission characteristics would serve as 
input data, whereas $\mathrm{Q}_{\text {in }}$ and $\mathrm{Q}_{\text {out }}$ would results as output calculations or resulting from boundary conditions.

\section{Conclusion}

In this paper, we have shown that the innovative experimental approach resulting from the combined use of three techniques, namely the oxygen bomb calorimetry, the pyrolysis flow calorimetry and the fire calorimetry based on the operation of the Fire Propagation Apparatus, allows for the provision of very useful and consistent information regarding many aspects of flammability of ILs that can in turn feed contextual fire risk analysis for given IL applications. This has been illustrated by testing 12 of them, splitting into two major families: IMBILs and PBILs. It is confirmed that the fundamental properties of ILs (like very low volatility) in their native form does mean that these materials are harder to ignite, ever for ILs associated to reactive anions like [DCA]; this claim is true. However, the difficulty in ignition can be offset by external sources of energy and once ignited by significantly high heat releases when the materials finally ignite and burn under forced conditions.

Interestingly, many ILs show self-extinguishing behaviour under the sole radiation of the experimental pool fires at small scale. However, how this would translate to real world fire fighting behaviour is not clear at this time. The three techniques used in this paper complement clearly each other, bringing in a logical order of use [e.g.: (a) OB calorimetry, b) PCFC c) FPA], sets of valuable information in order to progress knowledge of ILs flammability for serving fire safety engineering that can be performance based (e.g. meeting prerequisite safety goals), instead of relying on prescriptive codes. Another outstanding result of our work per se is the production of the combustion characteristics of a set of ILs, among the most popular, including detailed identification and quantification of combustion products.

As also shown, the oxygen bomb calorimeter may serve as a checking process of the current domain of validity of dedicated predictive model that have previously established by same authors of this manuscript. Also worth to mention, the association of predictive tools (quantitative structure-property relationship model for assessing heats of combustion of ILs...) and experimental techniques allows for a proactive fire hazard analysis in the early stages of development of any new IL (about 150 are commercialized today, but thousands of them might be synthesised in the future!), depending of sample availability for testing: no sample is requested to predict heat of combustion, confirmation and first order thermal threat may be confirmed at the micro-scale, and some $20 / 25 \mathrm{~g}$ of sample allows for full implementation of 
our approach, including making use of the FPA and proceeding to first order evaluation of fire induced toxicity.

At last, the authors reasonably hope that their work brings a new step forward to greener use of those fascinating chemicals that are ILs and that persisting misleading statements about non flammability of ILs will be corrected by all stakeholders in soon future.

\section{Acknowledgements}

The authors would like to thank CYTEC Canada, Inc., Niagara Falls, ON, for supplying phosphonium samples and BASF Ludwigshafen, Germany, for supplying imidazolium samples. Special thanks are addressed to Jean-Pierre Bertrand for having conducted the experiments on the Tewarson calorimetry. This work was supported in part by the "IEED PIVERT" project and was funded, in part, by the U.S. Department of Commerce, National Institute of Standards and Technology, under Grant 12 \# 70NANB9H9183. 


\section{References}

1. A. Stark, Energy Environ. Sci., 2011, 4, 19.

2. Y. Wang, H. Li, C. Wang and H. Jiang, Chem. Commun., 2004, 17, 1938.

3. C. Roosen, P. Müller and L. Greiner, Appl Microbiol Biotechnol., 2008, 81(4), 607.

4. Y. Zhang and J.Y.G. Chan, Energy Environ. Sci., 2010, 3, 408.

5. L.D. Simoni, A. Chapeaux, J.F. Brennecke and M.A. Stadtherr, Comput. Chem. Eng., 2010, 34(9), 1406.

6. P. Weerachanchai, S.S.J. Leong, M.W. Chang, C.B. Ching and J-M. Lee, Bioresour. Technol., 2012, 111(0), 453.

7. H.F. Xiang, B. Yin, H. Wang H, H.W. Lin, X.W. Ge, S. Xie and C.H. Chen, Electrochim. Acta., 2010, 55(18), 5204.

8. A. Brandt, M.J. Ray, T.Q. To, D. J. Leak, R.J. Murphy and T. Welton, Green Chem., 13(9), 2489.

9. A-E. Jiménez and M-D. Bermúdez, Tribol Lett., 2006, 26(1), 53.

10. M. Hasib-ur-Rahman, M. Siaj and F. Larachi, Chem. Eng. Process., 2010, 49(4), 313.

11. J.F. Wishart, Energy Environ. Sci., 2009, 2(9), 956.

12. H. Sakaebe, H. Matsumoto, and K. Tatsumi, Electrochim. Acta, 2007, 53(3), 1048.

13. N.V. Likhanova, D. Guzmán-Lucero, E.A. Flores, P. García, M.A. Domínguez-Aguilar, J. Palomeque and R. Martínez-Palou, Mol Divers., 2010, 14(4), 777.

14. Regulation (EC) No 1272/2008 of the European Parliament and of the Council of 16 December 2008 on Classification, labelling and packaging of substances and mixtures, mending and repealing, European Parliament and of the Council, Directives 67/548/EEC and 1999/45/EC, and amending Regulation (EC) No 1907/2006. (http://eurlex.europa.eu/LexUriServ/LexUriServ.do?uri=CONSLEG:2008R1272:20110419:en:PDF) (Accessed October 2012).

15. Globally Harmonized System of Classification and Labelling of Chemicals, $4^{\text {th }}$ revised edition, New York and Geneva, 2011.

16. B. Kirchner, In Ionic Liquids. Topics in Current Chemistry, $1^{\text {st }}$ ed.; Springer-Verlag: Berlin, 2010; Vol. 290. 
17. M. Smiglak, W.M. Reichert, J.D. Holbrey, J.S. Wilkes, L. Sun, J.S. Thrasher, K. Kirichenko, S. Singh, A.R. Katritzky and R.D. Rogers, Chem. Commun., 2006, 24, 2554.

18. A.O. Diallo, A.B. Morgan, C. Len and G. Marlair, Sep. Purif. Technol., 2012, 97, 228.

19. D.M. Fox, J. Gilman, A.B. Morgan, J.R. Shields, P.H. Maupin, R.E. Lyon, H.C. De Long and P.C. Trulove, Ind. Eng. Chem. Res., 2008, 47(16), 6327.

20. D.M. Fox, W.H. Awad, J.W. Gilman, P. H. Maupin, H.C. De Long and P.C. Trulove, Green Chem., 2003, 5(6),724.

21. A.B. Morgan, Interflam, 2010, 12(1), 269.

22. A.O. Diallo, G. Fayet, C. Len, and G. Marlair, Ind. Eng. Chem. Res., 2012, 51(7), 3149.

23. ASTM D240-09 Standard Test Method for Heat of Combustion of Liquid Hydrocarbon Fuels by Bomb Calorimeter.

24. R. Walters and R.E. Lyon, US Patent 5981 290, 1999, 9.

25. ASTM D7309-07 Standard Test Method for Determining Flammability Characteristics of Plastics and Other Solid Materials Using Microscale Combustion Calorimetry.

26. C.Q. Yang, Q. He, R.E. Lyon and Y. Hu, Polym. Degrad. Stab., 2010, 95(2), 108.

27. A.B. Morgan and M. Galaska, Polym. Adv. Technol., 2008, 19(6), 530.

28. P.M. Hergenrother, C.M. Thompson, J.G. Smith, J.W. Connell, J.A. Hinkley, R.E. Lyon and R. Moulton, J. Appl. Polym. Sci., 2005, 46(14), 5012.

29. J.L. Jurs and J.M. Tour, J. Appl. Polym. Sci., 2003, 44(13), 3709.

30. H. Zhang, R.J. Farris and P.R. Westmoreland, Macromolecules, 2003, 36(11), 3944.

31. NFPA 287: Standard Test Methods for Measurement of Flammability of Materials in Cleanrooms Using a Fire Propagation Apparatus (FPA), 2001 Edition.

32. ASTM E2058-03 Standard Test Methods for Measurement of Synthetic Polymer Material Flammability Using a Fire Propagation Apparatus (FPA), ASTM International, W. Conshohocken, PA, 2006.

33. ISO 12136:2011 Reaction to fire tests - Measurement of material properties using a fire propagation apparatus.

34. S. Brohez, G. Marlair and C. Delvosalle, Fire Mater., 2006, 30(2), 131. 
35. S. Brohez, G. Marlair and C. Delvosalle, Fire Mater., 2006, 30(1), 35.

36. P. Ribière, S. Grugeon, M. Morcrette, S. Boyanov, S. Laruellea and G. Marlair, Energy Environ. Sci., 2012, 5, 5271.

37. G. Marlair and A. Tewarson, Fire Safety Science, proceedings of the $7^{\text {th }}$ International Symposium, Wocester MA (USA), 629-640.

38. K. Chen, J.C. Mackie, E.M. Kennedy and B.Z. Dlugogorski, Prog. Energ. Combust., 2012, 38, 400 .

39. C. Huggett, Fire Mater., 1980, 4(2), 61.

40. J.E. Mark, Physical Properties of Polymers Handbook. $2^{\text {nd }}$ Revised edition. SpringerVerlag New York Inc., 2007.

41. ISO 13571:2012 Life-threatening components of fire - Guidelines for the estimation of time available for escape using fire data.

42. R.N. Walters and R.E. Lyon, J. Appl. Polym. Sci., 2003, 87(3), 548.

43. M. Armand, F. Endres, D.R. MacFarlane, H. Ohno and B. Scrosati, Nat. Mater., 2009, 8, 621.

44. J.A. Lazzús, J. Mol. Liq., 2012, 168, 87.

45. E. Ufuah and C.G. Bailey, Proceedings of the World Congress on Engineering. 2011;III:1952. 


\section{Figure Captions}

Figure 1: Structures of the cations and anions used in this study

Figure 2: Operating principle of the Pyrolysis Combustion Flow Calorimeter (courtesy Richard E. Lyon)

Figure 3: Schematic view of the FPA calorimeter system and instrument picture

Figure 4: Modelling of generation of pollutants in an accidental fire scenario

Figure 5: Correlation plot of the calculated gross heats of combustion using IL-dedicated model versus experimental gross heats of combustion for the ILs used in this work (line is $\mathrm{y}=\mathrm{x})$

Figure 6: Combustion heat flux as a function of time during the combustion of IMBILs

Figure 7: Combustion heat flux as a function of time during the combustion of PBILs

Figure 8: Comparison between total heat release from PCFC and FPA calorimeter

Figure 9: Evolution of fractional effective doses of toxic gas involved in accidental fire scenario for a) IMBILs and b) PBILs, line for $\tau=3$, dash for $\tau=5$ and $\operatorname{dot}$ for $\tau=10$

Figure 10: Evolution of fractional effective concentration of irritant gas involved in accidental fire scenario for a) IMBILs and b) PBILs, line for $\tau=3$, dash for $\tau=5$ and dot for $\tau$ $=10$ 
Figure 1: Structures of the cations and anions used in this study

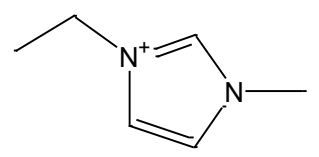

1-Ethyl-3-methylimidazolium [EMIM]

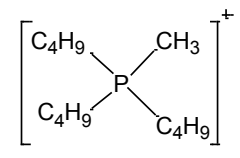

Tributyl(methyl)phosphonium $\left[\mathrm{P}_{4,4,4,1}\right]$

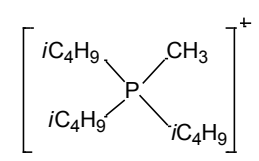

Triisobutyl(methyl)phosphonium $\left[\mathrm{P}_{\mathrm{i} 4, \mathrm{i} 4, \mathrm{i} 4,1}\right]$

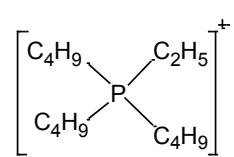

Tri(butyl)ethylphosphonium $\left[\mathrm{P}_{4,4,4,2}\right]$

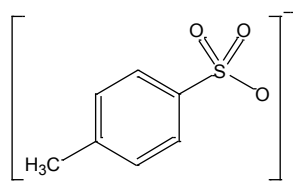

p-toluenesulfonate [TOS]

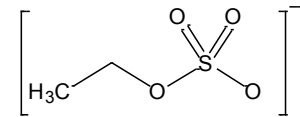

Ethylsulfate $\left[\mathrm{EtOSO}_{3}\right]$

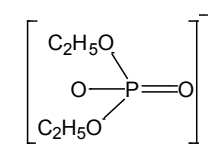

Diethylphosphate [DEP] Trifluoromethanesulfonate [OTf]

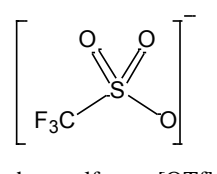

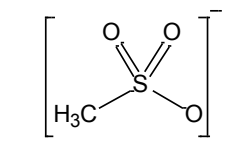

Methanesulfonate $\left[\mathrm{MeSO}_{3}\right]$

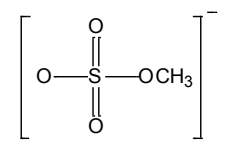

Methylsulfate $\left[\mathrm{MeOSO}_{3}\right]$

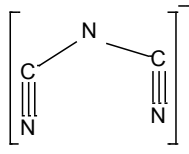

Dicyanamide [DCA]

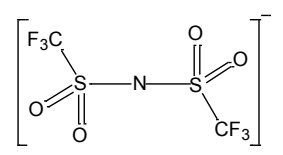

Bis(trifluoromethylsulfonyl)imide [TFSI]

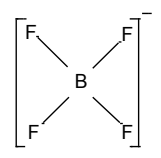

Tetrafluoroborate $\left[\mathrm{BF}_{4}\right]$

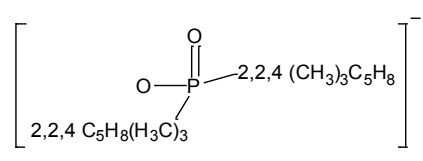

$\mathrm{Cl}$ 
Figure 2: Operating principle of the Pyrolysis Combustion Flow Calorimeter (courtesy Richard E. Lyon)

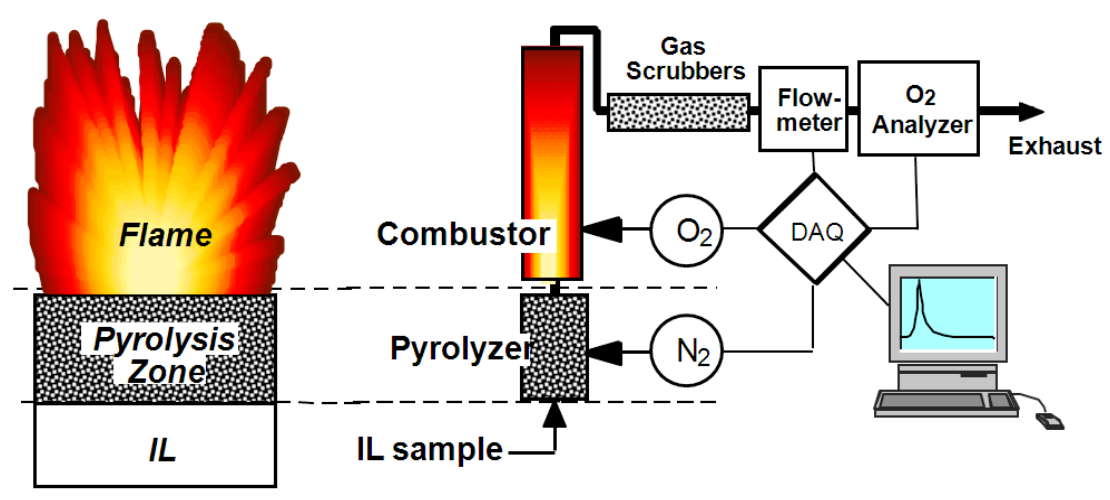


Figure 3: Schematic view of the FPA calorimeter system and instrument picture

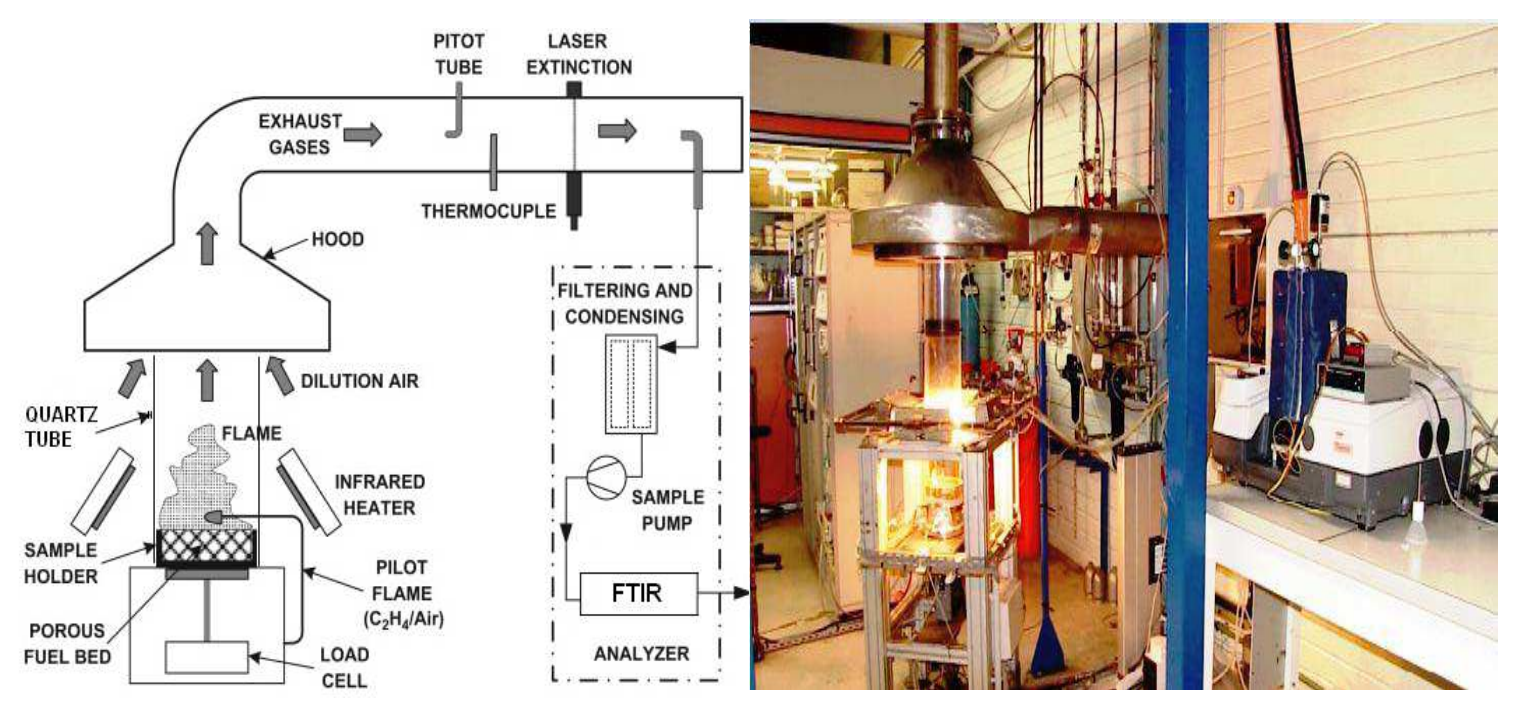


Figure 4: Modelling of generation of pollutants in an accidental fire scenario

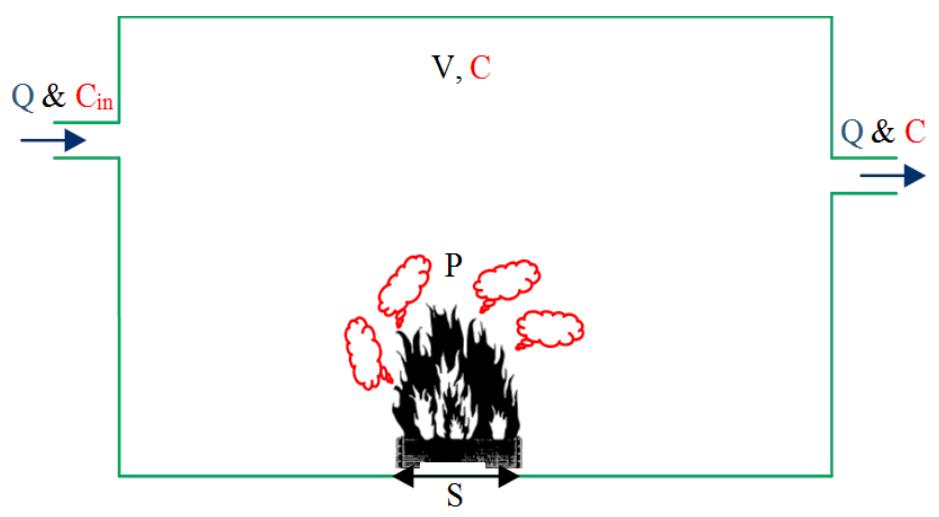


Figure 5: Correlation plot of the calculated gross heats of combustion using IL-dedicated model versus experimental gross heats of combustion for the ILs used in this work (dot is $\mathrm{y}=\mathrm{x})$

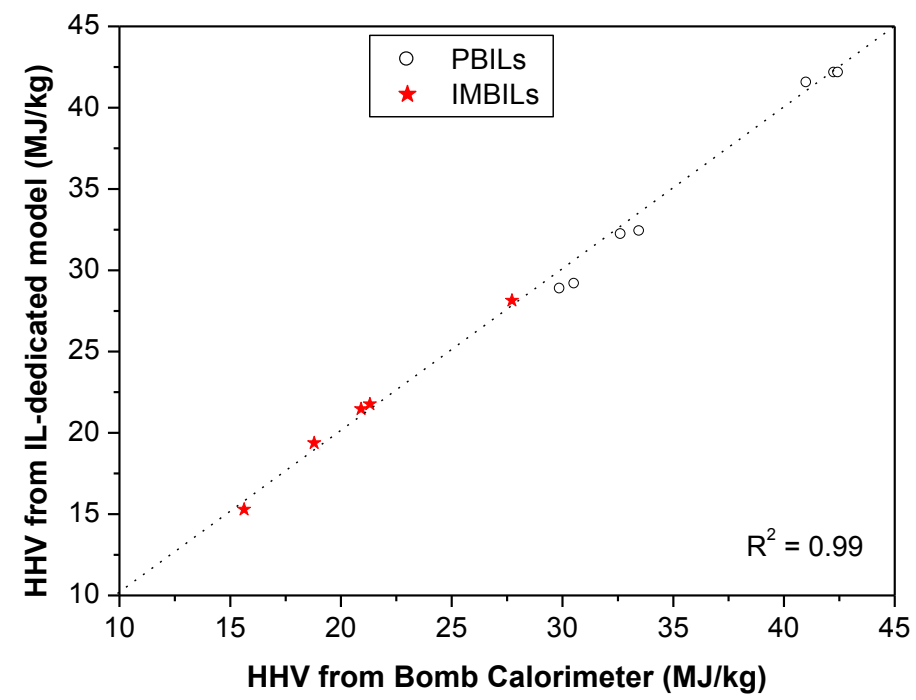


Figure 6: Combustion heat flux as a function of time during the combustion of IMBILs
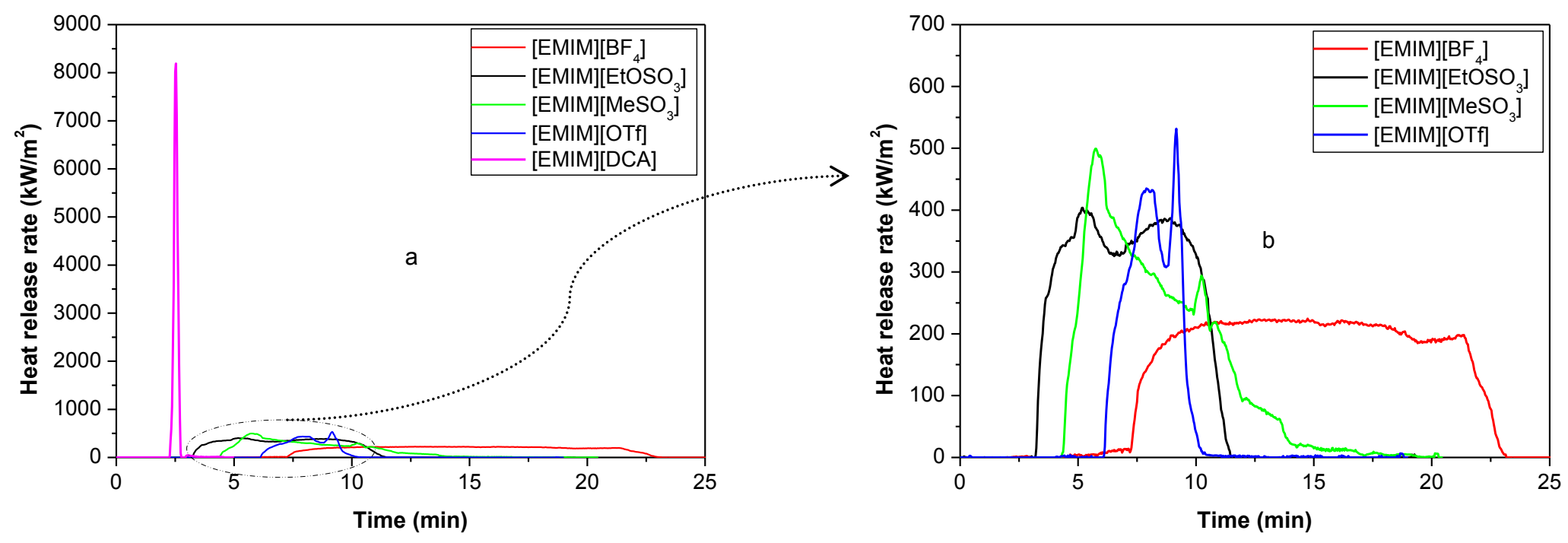
Figure 7: Combustion heat flux as a function of time during the combustion of PBILs
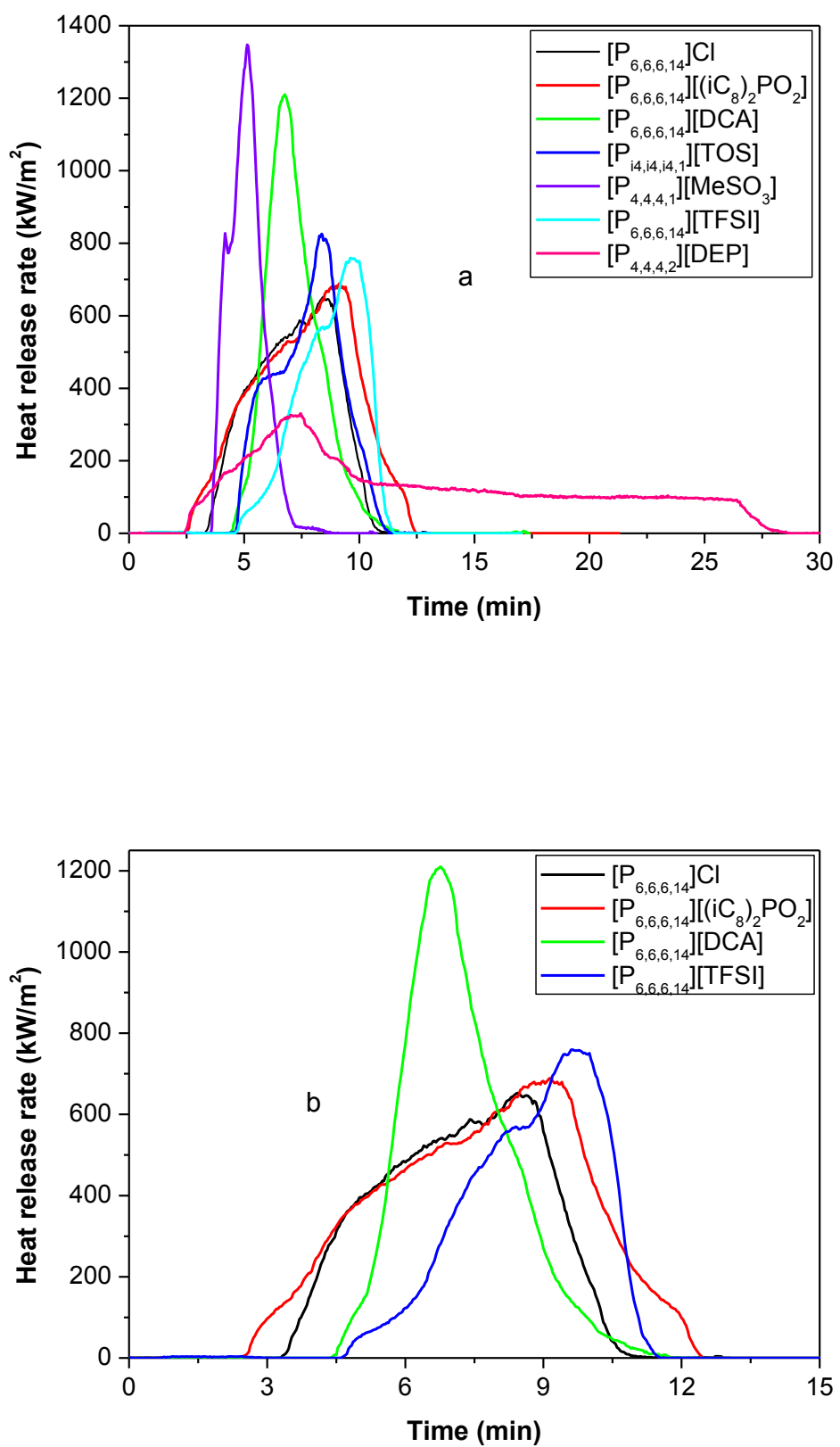
Figure 8: Comparison between total heat release from PCFC and FPA calorimeter

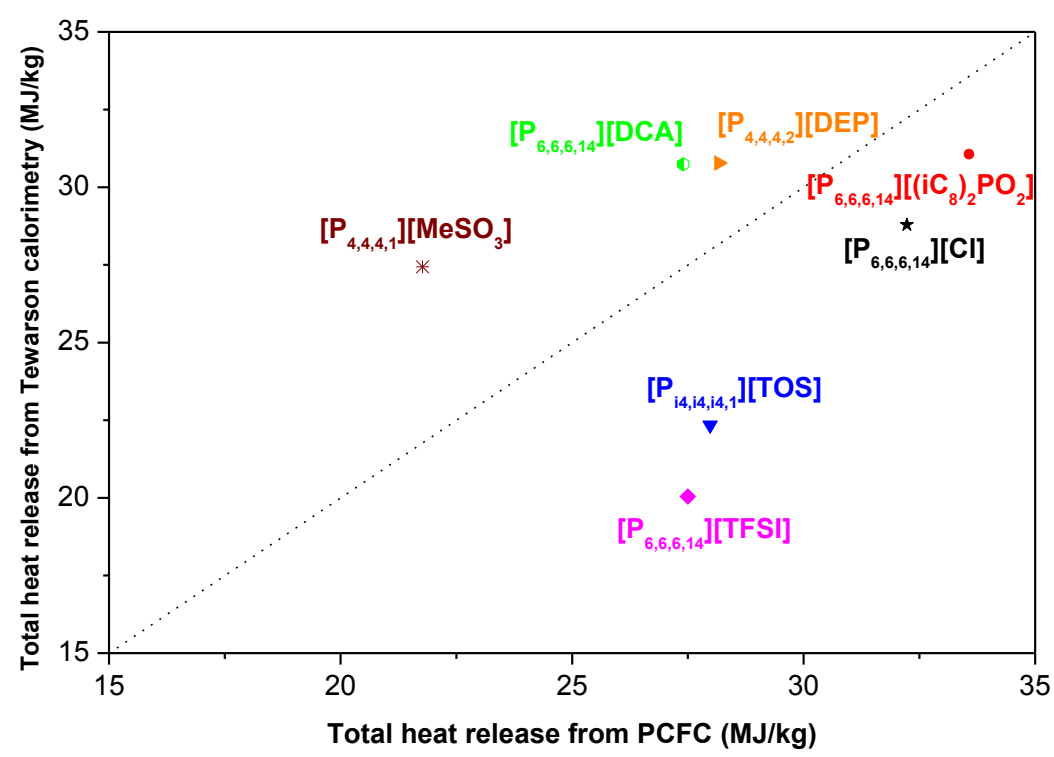


Figure 9: Evolution of fractional effective doses of toxic gas involved in accidental fire scenario for a) IMBILs and b) PBILs, line for $\tau=3$, dash for $\tau=5$ and dot for $\tau=10$
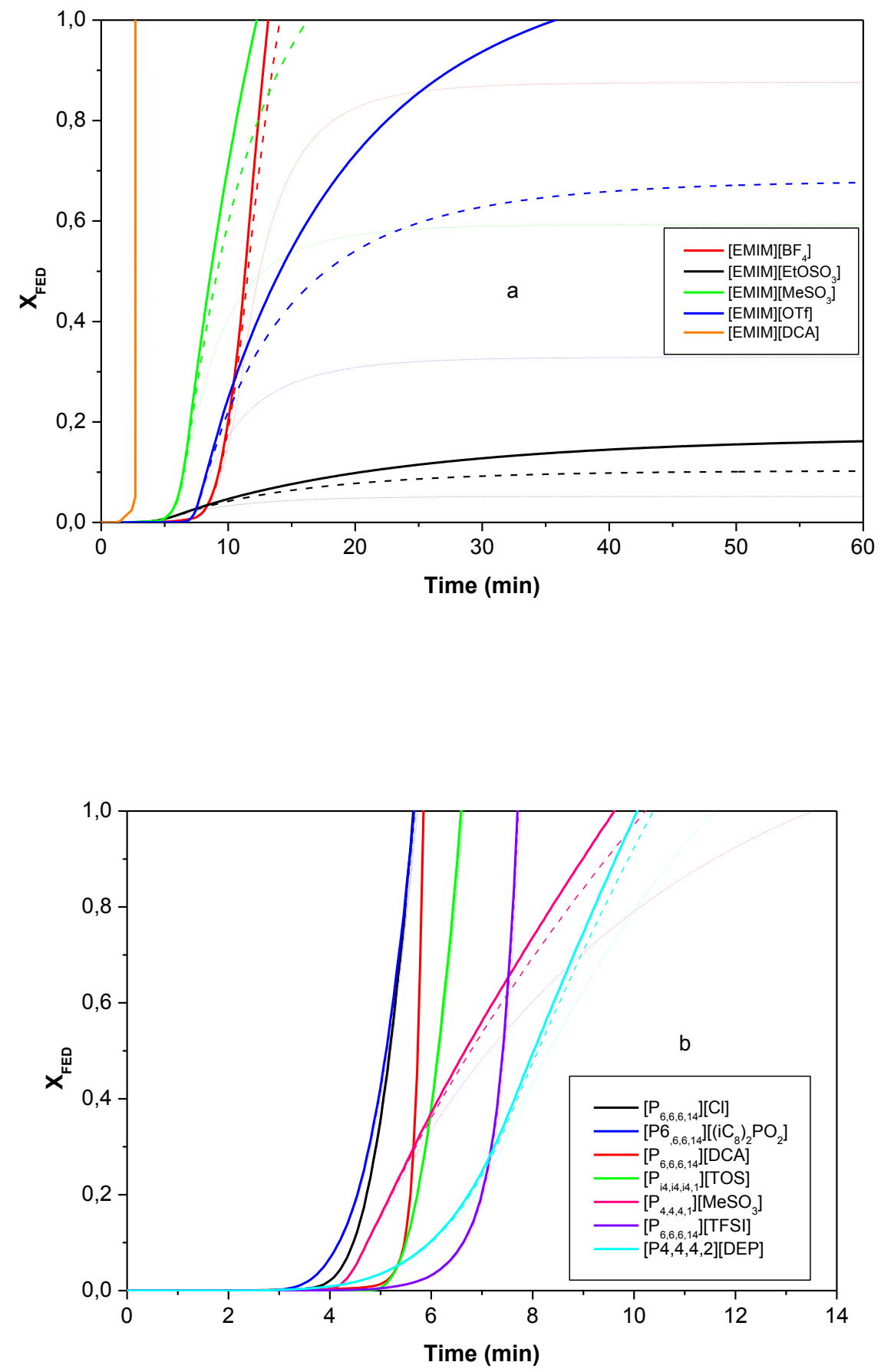
Figure 10: Evolution of fractional effective concentration of irritant gas involved in accidental fire scenario for a) IMBILs and b) PBILs, line for $\tau=3$, dash for $\tau=5$ and dot for $\tau$ $=10$
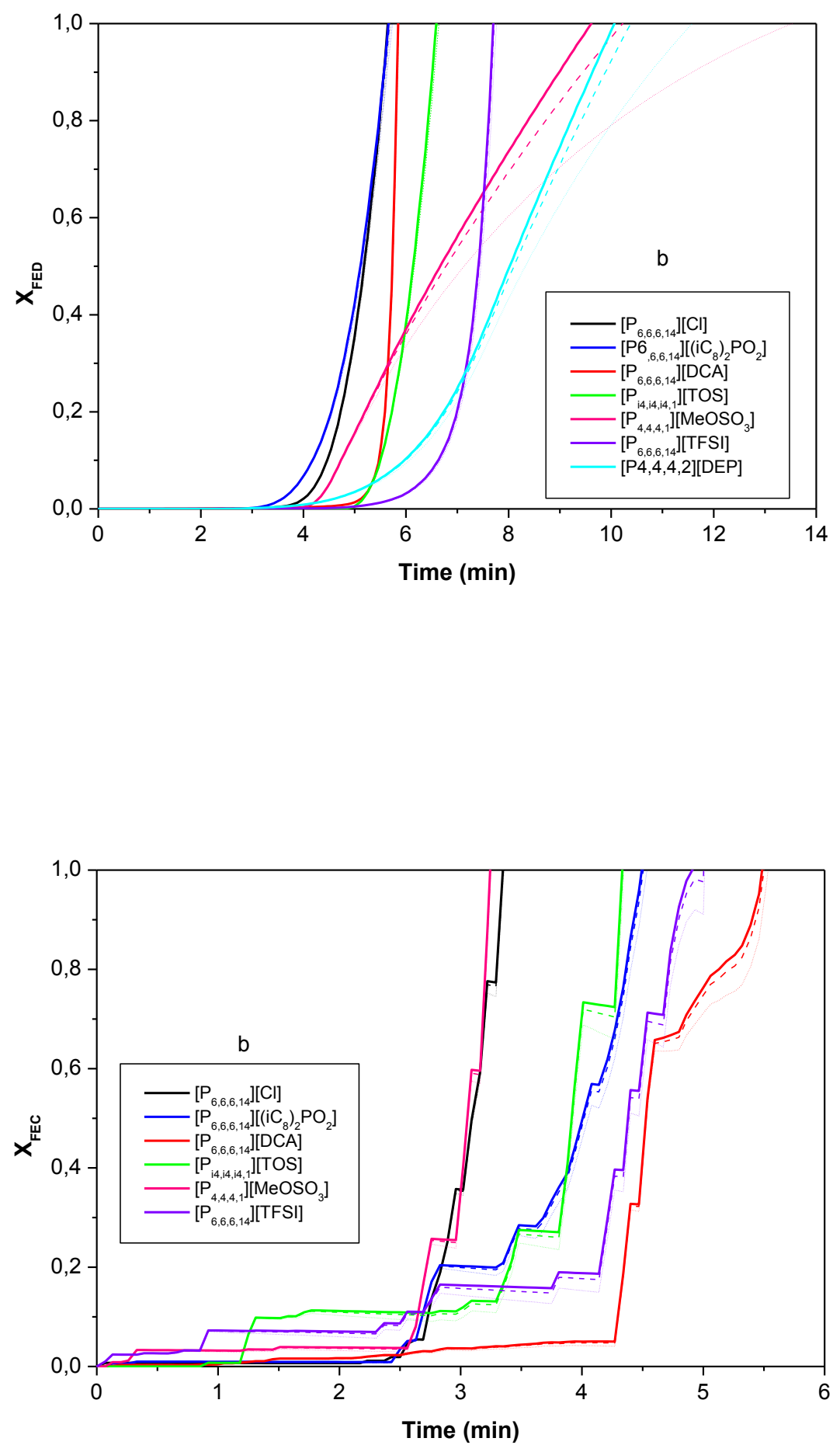


\section{Table captions}

Table 1: Mains characteristics of the studied ionic liquids

Table 2: Comparison of experimental gross heats of combustion to IL-dedicated model values

Table 3: Heat release rate data for phosphonium-based ionic liquid samples tested with the PCFC

Table 4: Burning behaviour of ionic liquids in the Fire Propagation Apparatus 
Table 1: Mains characteristics of the studied ionic liquids

\begin{tabular}{|c|c|c|c|c|c|}
\hline Ionic liquid & Supplier & Designation & $\begin{array}{l}\text { Molecular } \\
\text { formula }\end{array}$ & Molecular weight & Purity ${ }^{(a)}$ \\
\hline$\left[\mathrm{P}_{6,6,6,14}\right][\mathrm{Cl}]$ & CYTEC & Cyphos IL 101 & $\mathrm{C}_{32} \mathrm{H}_{68} \mathrm{ClP}$ & 519.31 & 96.4 \\
\hline$\left[\mathrm{P}_{6,6,6,14}\right]\left[\left(\mathrm{iC}_{8}\right)_{2} \mathrm{PO}_{2}\right]$ & CYTEC & Cyphos IL 104 & $\mathrm{C}_{48} \mathrm{H}_{102} \mathrm{O}_{2} \mathrm{P}_{2}$ & 773.27 & 95.0 \\
\hline$\left[\mathrm{P}_{6,6,6,14}\right][\mathrm{DCA}]$ & CYTEC & Cyphos IL 105 & $\mathrm{C}_{34} \mathrm{H}_{68} \mathrm{~N}_{3} \mathrm{P}$ & 549,90 & 95.7 \\
\hline$\left[\mathrm{P}_{\mathrm{i} 4, \mathrm{i} 4, \mathrm{i} 4,1}\right][\mathrm{TOS}]$ & CYTEC & Cyphos IL 106 & $\mathrm{C}_{20} \mathrm{H}_{37} \mathrm{O}_{3} \mathrm{PS}$ & 388.55 & $>99.0\left(<0.6[\mathrm{iPr}]_{3} \mathrm{P} ;<0.1 \mathrm{MeOT}\right)$ \\
\hline$\left[\mathrm{P}_{4,4,4,1}\right]\left[\mathrm{MeOSO}_{3}\right]$ & CYTEC & Cyphos IL 108 & $\mathrm{C}_{14} \mathrm{H}_{33} \mathrm{O}_{4} \mathrm{PS}$ & 328.45 & 96.7 \\
\hline$\left[\mathrm{P}_{6,6,6,14}\right][$ TFSI $]$ & CYTEC & Cyphos IL 109 & $\mathrm{C}_{34} \mathrm{H}_{68} \mathrm{~F}_{6} \mathrm{NO}_{4} \mathrm{PS}_{2}$ & 764.00 & 97.8 \\
\hline$\left[\mathrm{P}_{4,4,4,2}\right][\mathrm{DEP}]$ & CYTEC & Cyphos IL 169 & $\mathrm{C}_{18} \mathrm{H}_{42} \mathrm{O}_{4} \mathrm{P}_{2}$ & 384.47 & 96.3 \\
\hline$[\mathrm{EMIM}]\left[\mathrm{MeSO}_{3}\right]$ & BASF & Basionics ${ }^{\mathrm{TM}}$ ST 35 & $\mathrm{C}_{7} \mathrm{H}_{14} \mathrm{~N}_{2} \mathrm{O}_{3} \mathrm{~S}$ & 206.26 & $\geq 95.0\left(\leq 0.5 \mathrm{w} ; \leq 2 \mathrm{Cl}^{-}\right)$ \\
\hline$[\mathrm{EMIM}]\left[\mathrm{EtOSO}_{3}\right]$ & BASF & Basionics ${ }^{\mathrm{TM}}$ LQ 01 & $\mathrm{C}_{8} \mathrm{H}_{16} \mathrm{~N}_{2} \mathrm{O}_{4} \mathrm{~S}$ & 236.29 & $\geq 95.0$ \\
\hline$[\mathrm{EMIM}][\mathrm{DCA}]$ & BASF & Basionics ${ }^{\mathrm{TM}}$ VS 03 & $\mathrm{C}_{8} \mathrm{H}_{11} \mathrm{~N}_{5}$ & 177.21 & $\geq 98.0(\leq 1.0 \mathrm{w})$ \\
\hline$[\mathrm{EMIM}]\left[\mathrm{BF}_{4}\right]$ & BASF & Basionics ${ }^{\mathrm{TM}}$ EE 03 & $\mathrm{C}_{6} \mathrm{H}_{11} \mathrm{BF}_{4} \mathrm{~N}_{2}$ & 197.97 & $\geq 98.0(\leq 0.5 \mathrm{w})$ \\
\hline [EMIM][OTf] & BASF & Basionics ${ }^{\mathrm{TM}} \mathrm{VS} 11$ & $\mathrm{C}_{7} \mathrm{H}_{11} \mathrm{~F}_{3} \mathrm{~N}_{2} \mathrm{O}_{3} \mathrm{~S}$ & 260.23 & $\geq 98.0(\leq 0.5 \mathrm{w})$ \\
\hline
\end{tabular}

${ }^{\mathrm{a}}$ As received from the supplier. $[\mathrm{iPr}]_{3} \mathrm{P}$, triisobutylphosphine; w, water; $\mathrm{Cl}^{-}$, chlorine. 
Table 2: Comparison of experimental gross heats of combustion to IL-dedicated model values

\begin{tabular}{|c|c|c|c|}
\hline Sample & Predicted value $(\mathrm{MJ} / \mathrm{kg})$ & Measured value (MJ/kg) & $\%$ error \\
\hline$\left[\mathrm{P}_{6,6,6,14}\right][\mathrm{Cl}]$ & 42.12 & $42.28 \pm 0.08$ & -0.39 \\
\hline$\left[\mathrm{P}_{6,6,6,14}\right]\left[\left(\mathrm{iC}_{8}\right)_{2} \mathrm{PO}_{2}\right]$ & 42.12 & $42.47 \pm 0.08$ & -0.83 \\
\hline$\left[\mathrm{P}_{6,6,6,14]}[\mathrm{DCA}]\right.$ & 41.52 & $41.04 \pm 0.08$ & +1.17 \\
\hline$\left[\mathrm{P}_{\mathrm{i} 4, \mathrm{i} 4, \mathrm{i} 4,1][\mathrm{TOS}]}\right.$ & 32.37 & $33.49 \pm 0.08$ & -3.35 \\
\hline$\left[\mathrm{P}_{4,4,4,1}\right]\left[\mathrm{MeOSO}_{3}\right]$ & 29.13 & $30.55 \pm 0.08$ & -4.64 \\
\hline$\left[\mathrm{P}_{6,6,6,14}\right][\mathrm{TFSI}]$ & 28.84 & $29.90 \pm 0.08$ & -3.53 \\
\hline$\left[\mathrm{P}_{4,4,4,2}\right][\mathrm{DEP}]$ & 32.19 & $32.65 \pm 0.08$ & -1.41 \\
\hline$[\mathrm{EMIM}]\left[\mathrm{MeSO}_{3}\right]$ & 21.77 & $21.31 \pm 0.08$ & +2.16 \\
\hline$[\mathrm{EMIM}]\left[\mathrm{EtOSO}_{3}\right]$ & 21.47 & $20.91 \pm 0.08$ & +2.68 \\
\hline$[$ EMIM] $[\mathrm{DCA}]$ & 28.14 & $27.72 \pm 0.08$ & +1.52 \\
\hline$[\mathrm{EMIM}]\left[\mathrm{BF}_{4}\right]$ & 19.38 & $18.79 \pm 0.08$ & +3.14 \\
\hline$[\mathrm{EMIM}][\mathrm{OTf}]$ & 15.29 & $15.63 \pm 0.08$ & -2.18 \\
\hline
\end{tabular}


Table 3: Heat release rate data for phosphonium-based ionic liquid samples tested with the PCFC

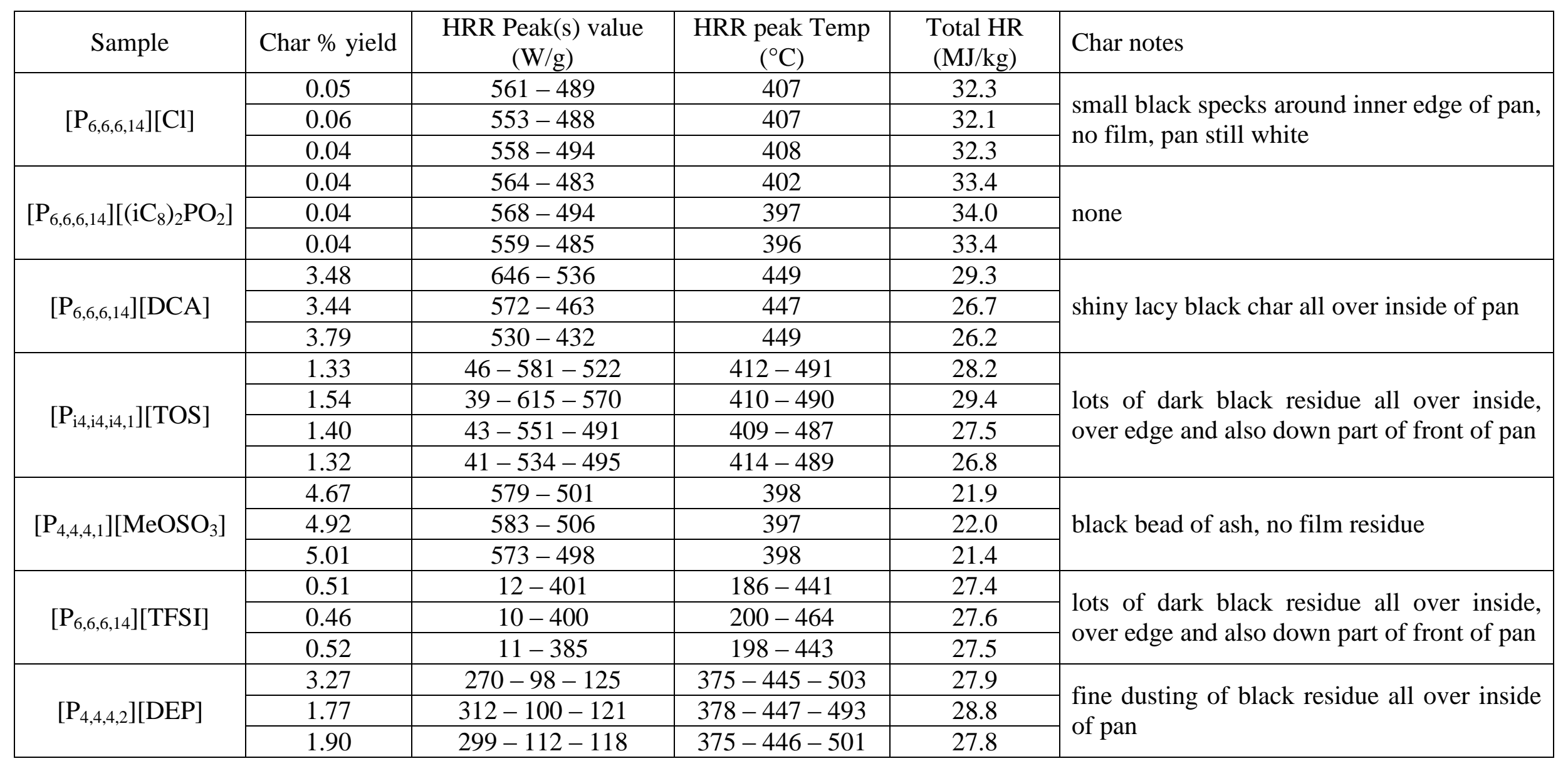


Table 4: Burning behaviour of ionic liquids in the Fire Propagation Apparatus

\begin{tabular}{|c|c|c|c|c|c|c|c|c|c|c|c|c|}
\hline & $\begin{array}{c}{\left[\mathbf{P}_{6,6,6,14}\right]} \\
{[\mathbf{C l}]}\end{array}$ & $\begin{array}{c}{\left[\mathbf{P}_{6,6,6,614}\right]} \\
{\left[\left(\mathbf{i C}_{8}\right)_{2} \mathbf{P O}_{2}\right]}\end{array}$ & $\begin{array}{c}{\left[\mathbf{P}_{6,6,6,14}\right]} \\
{[\mathbf{D C A}]}\end{array}$ & $\begin{array}{c}{\left[\mathbf{P}_{\mathbf{i} 4, \mathbf{i} 4, \mathbf{i}, \mathbf{1}}\right]} \\
{[\mathrm{TOS}]}\end{array}$ & $\begin{array}{c}{\left[\mathbf{P}_{4,4,4,1}\right]} \\
{\left[\mathrm{MeOSO}_{3}\right]}\end{array}$ & $\begin{array}{c}{\left[\mathbf{P}_{6,6,6,14}\right]} \\
{[\text { TFSI }]}\end{array}$ & $\begin{array}{c}{\left[\mathbf{P}_{4,4,4,2}\right]} \\
{[\mathbf{D E P}]}\end{array}$ & $\begin{array}{l}{[\mathrm{EMIM}]} \\
{\left[\mathrm{MeSO}_{3}\right]}\end{array}$ & $\begin{array}{c}{\left[\mathrm{EMIM}^{-}\right]} \\
{\left[\mathrm{BF}_{4}\right]}\end{array}$ & $\begin{array}{c}\text { [EMIM] } \\
\text { [OTf] }\end{array}$ & $\begin{array}{c}{[\mathrm{EMIM}} \\
\left.\text { [EtOSO }_{3}\right]\end{array}$ & $\begin{array}{c}{[\text { EMIM] }} \\
\text { [DCA] }\end{array}$ \\
\hline External flux $\left(\mathbf{k W} / \mathbf{m}^{2}\right)$ & 50 then 25 & 50 then 25 & 50 then 25 & 50 then 25 & 50 then 25 & 50 then 25 & 50 then 25 & 50 then 25 & 50 then 25 & 50 then 25 & 50 then 25 & 50 then 0 \\
\hline Initial mass (g) & 37.2 & 44.3 & 37.8 & 49.7 & 32.5 & 47 & 50.3 & 50.6 & 59.7 & 64.3 & 52.5 & 22.4 \\
\hline Mass lost \% & 100 & 99.5 & 95 & 89.5 & 93.5 & 99.1 & 80.9 & 87.5 & 98.8 & 81.3 & 92.6 & 58.9 \\
\hline Char residue \% & 0 & 0.5 & 5 & 10.5 & 6.5 & 0.9 & 9.1 & 12.5 & 1.2 & 18.7 & 7.4 & $(41.1)^{(a)}$ \\
\hline Time to ignition (s) & 180 & 135 & 260 & 270 & 200 & 270 & 140 & 270 & 430 & 360 & 198 & 138 \\
\hline Average mass loss rate $\left(\mathrm{g} / \mathrm{m}^{2} / \mathrm{s}\right)$ & 17 & 15 & 25 & 24 & 33 & 26 & 4.5 & 14 & 11 & 43 & 18 & 187 \\
\hline Mass loss rate $\max \left(\mathrm{g} / \mathrm{m}^{2} / \mathrm{s}\right)$ & 24 & 25 & 40 & 40 & 50 & 42 & 11.5 & 23 & 14 & 155 & 38 & 224 \\
\hline phi max & 0.3 & 0.3 & 0.45 & 0.32 & 0.36 & 0.31 & 0.09 & 0.12 & 0.06 & 0.6 & 0.2 & 0.9 \\
\hline \multicolumn{13}{|c|}{ Heat of combustion $(\mathrm{MJ} / \mathrm{kg})$} \\
\hline Theoretical low heat of combustion & 39.38 & 39.55 & 38.30 & 31.38 & 28.32 & 27.32 & 30.23 & 19.80 & 17.56 & 14.70 & 19.41 & 26.34 \\
\hline OC method & 28.65 & 31.50 & 30.88 & 22.95 & 28.36 & 20.17 & 32.06 & 20.35 & 17.09 & 8.43 & 20.16 & 23.95 \\
\hline CDG method & 28.92 & 30.56 & 30.60 & 21.72 & 26.52 & 19.9 & 29.50 & 17.82 & 17.86 & 7.78 & 18.60 & 25.51 \\
\hline Average & 28.79 & 31.03 & 30.74 & 22.34 & 27.44 & 20.04 & 30.78 & 19.09 & 17.48 & 8.11 & 19.38 & 24.73 \\
\hline Energy efficiency \% & 73 & 78 & 80 & 71 & 97 & 73 & 101 & 96 & 99 & 55 & 99 & 94 \\
\hline \multicolumn{13}{|c|}{ Emission factor (mg of pollutant per g of IL burnt) } \\
\hline $\mathrm{CO}_{2}$ & 1545 & 1840.2 & 1854.6 & 1175.3 & 1653.9 & 1228.5 & 1858 & 1334.9 & 1184.8 & 640.2 & 1400.6 & 1622.7 \\
\hline $\mathrm{CO}$ & 228.7 & 240.6 & 183.8 & 223.4 & 36.0 & 131.3 & 92.5 & 9.3 & 5.0 & 3.9 & 1.0 & 66.5 \\
\hline Soot & 144.6 & 91.8 & 116.0 & 147.3 & 48.8 & 65.0 & 95.0 & 6.4 & $126.0^{(\mathrm{c})}$ & 4.9 & - & 8.1 \\
\hline $\mathrm{HCt}$ & 65.3 & 48.5 & 42.5 & 61.4 & 3.4 & 38.1 & 3.1 & 2.1 & 3.5 & 2.6 & 1.6 & 38.0 \\
\hline $\mathrm{CH}_{4}$ & 9.8 & 9.2 & 5.3 & 11.9 & 0.2 & 4.3 & 0.5 & 0.3 & - & - & - & 4.6 \\
\hline $\mathrm{C}_{2} \mathrm{H}_{2}$ & 14.2 & 7.4 & 9.7 & 2.9 & - & 4.9 & - & - & - & - & - & 6.4 \\
\hline $\mathrm{C}_{2} \mathrm{H}_{4}$ & 10.3 & 9.8 & 6.6 & 5.3 & - & 5.1 & 0.6 & - & 0.7 & 1.6 & 0.3 & 3.4 \\
\hline $\mathrm{CH}_{2} \mathrm{O}$ & 4.7 & 7.0 & 6.1 & 3.8 & 1.8 & 4.1 & - & - & - & - & - & 1.3 \\
\hline $\mathrm{SO}_{2}$ & - & - & - & 138.6 & 184.0 & 138.0 & - & 344.8 & - & 160.7 & 294.2 & - \\
\hline NO & - & - & 5.7 & - & - & 3.6 & - & 15.2 & 7.7 & 6.3 & 17.2 & 9.3 \\
\hline $\mathrm{NO}_{2}$ & - & - & - & - & - & 0.1 & - & 0.5 & - & 0.1 & - & 0.3 \\
\hline $\mathrm{N}_{2} \mathrm{O}$ & - & - & 2.4 & - & - & 0.5 & - & 1.0 & 3.2 & 0.6 & 0.1 & 3.9 \\
\hline $\mathbf{N H}_{3}$ & - & - & - & - & - & 0.1 & - & - & - & - & - & - \\
\hline $\mathrm{HCl}$ & 70.1 & - & - & - & - & - & - & - & - & - & - & - \\
\hline HF & - & - & - & - & - & 81.7 & - & - & 243.8 & $118.5^{\text {(d) }}$ & - & - \\
\hline $\mathrm{SiF}_{4}$ & - & - & - & - & - & 28.5 & - & - & 44.6 & 13.0 & - & - \\
\hline $\mathbf{B F}_{3}$ & - & - & - & - & - & - & - & - & $26.2^{(\mathrm{d})}$ & - & - & - \\
\hline HCN & - & - & 12.8 & - & - & 2.9 & - & 1.4 & 0.9 & 1.0 & - & $46.3^{(\mathrm{d})}$ \\
\hline Carbon efficiency (without residue) \% ${ }^{\text {(b) }}$ & 100 & 97.6 & 95.5 & 94.7 & 92.1 & 92.1 & 90.3 & 81.1 & $124.9^{(\mathrm{c})}$ & 44.8 & 89.2 & 59.9 \\
\hline Chlorine conversion efficiency $\%^{(b)}$ & 99.8 & - & - & - & - & - & - & - & - & - & - & - \\
\hline Fluorine conversion efficiency $\%^{(b)}$ & - & - & - & - & - & 65.4 & - & - & 73.7 & 45.3 & - & - \\
\hline Sulphur conversion efficiency $\%^{(b)}$ & - & - & - & 75.4 & 81.5 & 81.7 & - & 97.3 & - & 53.1 & 100.5 & - \\
\hline Nitrogen conversion efficiency \% (b) & - & - & 13.4 & - & - & 19.5 & - & 5.5 & 4.2 & 3.0 & 6.5 & 4.6 \\
\hline
\end{tabular}

Nitrogen conversion efficiency $\%$

${ }^{a}$ Residue formation process particularly important and that may have induce some error in final mass balance.

${ }^{\mathrm{b}}$ Element conversion efficiency here means total mass of parent (and measured) toxic/pollutant emissions (expressed in the designated element/versus element quantity bound to the test chemical).

${ }^{\mathrm{c}}$ Poor carbon balance, optical measurement of soots seems very high with regard to the $\mathrm{CO}$ and $\mathrm{HCt}$.

${ }^{\mathrm{d}}$ Concentration beyond the last standard. 